\title{
Protective effects of halophyte complex extract against UVB-induced damage in human keratinocytes and the skin of hairless mice
}

\author{
JAE YOUNG SHIN ${ }^{1,2}$, JI HYEON PARK ${ }^{3}$, DENIS NCHANG CHE ${ }^{1}$, \\ HYUN JU KANG ${ }^{2}$, BYOUNG OK CHO ${ }^{2,3}$, YITEAK LIM ${ }^{4}$ and SEON IL JANG ${ }^{2,3}$ \\ ${ }^{1}$ Department of Food Science and Technology, Jeonbuk National University, Jeonju-si, Jeollabuk-do 54896; \\ ${ }^{2}$ Research Institute, Ato Q\&A Co., Ltd., Jeonju-si, Jeollabuk-do 54840; \\ ${ }^{3}$ Department of Health Management, Jeonju University, Jeonju-si, Jeollabuk-do 55069; \\ ${ }^{4}$ Jinandang Farming Association Corporation, Jinan-gun, Jeollabuk-do 55442, Republic of Korea
}

Received November 6, 2020; Accepted February 23, 2021

DOI: $10.3892 /$ etm.2021.10114

\begin{abstract}
Limonium tetragonum, Triglochin maritimum, Artemisia scoparia and red ginseng have been used as folk remedies for treating a variety of diseases. In the current study, the protective effects of halophyte and red ginseng against ultraviolet (UV)-induced skin damage were investigated. Halophyte red ginseng complex extract (HRCE) was prepared and its effects on UV-B irradiated human keratinocytes and mouse skin were studied through ELISA, Western blotting immunofluorescence and histological staining. HRCE inhibited peroxide-induced damage in human keratinocytes. HRCE also inhibited UVB-induced collagen and elastin degradation in human keratinocytes and mouse skin. In addition, HRCE inhibited mast cell infiltration in the skin of mice irradiated with UVB light. This effect was likely due to HRCE inhibiting the activation of MAPK and NF- $\kappa \mathrm{B}$. By protecting the skin from UVB-induced skin damage, HRCE has the potential to be used in the treatment and prevention of UV-induced skin damage and photoaging.
\end{abstract}

\section{Introduction}

Skin is the largest organ in the body. It is the first barrier that protects the body from external agents. The skin consists of a stratum corneum composed of keratinized epithelial cells, an epidermis composed of keratinocytes, and a dermis containing fibrous collagen and elastin (1). Collagen is a major matrix protein produced by fibroblasts. It is particularly rich in the skin (dermis). Collagen contributes to mechanical

Correspondence to: Professor Seon Il Jang, Department of Health Management, Jeonju University, 303 Cheonjam-ro, Wansan-gu, Jeonju-si, Jeollabuk-do 55069, Republic of Korea

E-mail: sonjjang@jj.ac.kr

Key words: halophyte, red ginseng, ultraviolet B, photoaging firmness of the skin. It helps cell adhesion and induction of cell division and differentiation (2). Skin aging and damage are caused by UV light, genetic factors, oxidative stress, and environmental exposure. Skin aging is divided into photoaging caused by UV exposure and endogenous aging caused by physiological factors. However, UV exposure is the most common cause of skin damage and aging $(3,4)$. UV spectrum is divided into UV-A (320-400 nm), UV-B (290-320 nm), and UV-C (290-100 nm). In particular, UV-B causes oxidative stress such as reactive oxygen species (ROS) on the skin. It can result in transient and persistent DNA damage with increased expression of aging factors such as matrix metalloproteinase (MMPs) $(5,6)$. Increased expression of MMPs can degrade collagen in the dermis and reduce its production. Inhibited expression of MMPs is an important factor in regulating collagen metabolism and promoting collagen production $(7,8)$. MMP-1 is called collagenase. It mainly decomposes type 1 collagen in the dermis. Expression of MMPs is initiated by the activation of the MAPK signaling pathway by ROS (9). UVB stimulation can activate phosphorylation of ERK1/2, JNK, and p38 kinase. Activated MAP kinase can promote phosphorylation of p65 and p50 proteins as important subunits of the $\mathrm{NF}-\mathrm{\kappa B}$ transcription factor, thereby increasing the amount of transcription factors translocated into the nucleus. Activated and translocated into the nucleus, NF- $\kappa \mathrm{B}$ can promote the transcription of proteins such as MMP-1, resulting in collagen degradation $(10,11)$.

Limonium tetragonum is a biennial plant of the Plumbaginaceae family. This plant contains active ingredients such as myricetin, myricetin glycosides, tannins, and caprolactam. It has been used in folk medicine to treat uterine bleeding, oligomenorrhea, and dysgalactia (12). Triglochin maritimum is a perennial plant that has been reported to have antioxidant and anti-inflammatory effects (13). Artemisia scoparia is a perennial plant in the Asteraceae family found mainly in India and Pakistan. Its main chemical components have been reported to be flavonoids, coumarin, ketone, and chromogen (14). A. scoparia has been used as a folk remedy for its antipyretic, anticholesterol, antiseptic, 
antibacterial, diuretic, and vasodilator properties (15). Red ginseng is a herbal medicine that has been used for a long time in oriental medicine. Its main chemical component is ginsenoside. It has been reported to be effective in alleviating diseases related to oxidative stress (16). The purpose of this study was to investigate inhibitory effects of L.tetragonum, T. maritimum, A. scoparia, and red ginseng complex against UVB-induced photoaging and the mechanism of action involved in such effects.

\section{Materials and methods}

Materials. Dulbecco's modified Eagle medium (DMEM) and fetal bovine serum were purchased from Gibco; Thermo Fisher Scientific, Inc. Penicillin/streptomycin antibiotics came from Invitrogen; Thermo Fisher Scientific, Inc. EZ-Cytox reagent and EZ-western Lumi Pico Alpha were obtained from DoGenBio. Protease inhibitors, tert-butyl hydroperoxide (tBHP), L-ascorbic acid, and o-toluidine blue were purchased from Sigma-Aldrich. Radio-immunoprecipitation assay buffer (RIPA buffer) was purchased from Thermo Fisher Scientific, Inc. ELISA Kit for Collagen Type I was purchased from Cloud-Clone Corp.. Collagen, elastin, MMP-1, MMP-9, JNK, p-JNK, ERK, p-ERK, p38, p-p38, NF- $\mathrm{B}, \mathrm{P}-\mathrm{NF}-\kappa \mathrm{B}$, and HRP conjugated secondary antibody (Santa Cruz Biotechnology, Inc.) and actin antibody (Biosciences) were also used in this study.

Plant material and extract. Limonium tetragonum used in the experiment was collected from Sinsido. Artemisia scoparia was collected from Sohwangsagu. Triglochin maritimum Linnaeus was collected from Simwon-myeon. Plants were identified by Dr Ahn Jin-Gap. Red ginseng root was purchased from Jinandang Farming Association Corporation. Halophyte red ginseng complex extract (HRCE) was produced from raw materials of complex Limonium tetragonum 2: Artemisia scoparia 1: Triglochin maritimum 1: Red ginseng 2, and ethanol $50 \%$ with the extraction ratio of 20:1. HRCE was filtered using a $0.45-\mathrm{m}$ filter, concentrated with a rotary pressure reducer, dried with a freeze dryer, and stored at $-20^{\circ} \mathrm{C}$.

Cell culture. Human keratinocyte (HaCaT) cell line was purchased from CLS Cell Lines Service GmbH. These cells were cultured and maintained in DMEM media supplemented with $10 \%$ fetal bovine serum, $100 \mathrm{U} / \mathrm{ml}$ penicillin, and $100 \mu \mathrm{g} / \mathrm{ml}$ streptomycin in a $5 \% \mathrm{CO}_{2}$ incubator at $37^{\circ} \mathrm{C}$.

Animal and experimental design. Male hairless mice at five weeks of age were purchased from Orient Bio Inc. These mice were housed in an air-conditioned room with temperature of $22 \pm 2^{\circ} \mathrm{C}$, humidity of $50-60 \%$, and a $12 / 12 \mathrm{~h}$ day/night cycle. These mice were given a commercial-standard laboratory diet and water at will. All procedures were performed in compliance with guiding principles for animal care and use committee of Jeonju University Institutional Animal Care and Used Committee guidelines (approved no. JJU-IACUC-2018-5). Animals were adapted to the laboratory environment for one week prior to the experimentation. The number of mice in each experimental group was five. HRCE (200 mg/kg), HRCE
(100 mg/kg) + L-ascorbic acid (AA) $(25 \mathrm{mg} / \mathrm{kg})$, and $\mathrm{L}$-ascorbic acid (AA) $(50 \mathrm{mg} / \mathrm{kg})$ were dissolved in saline and oral administered at one week before UVB irradiation and continued until the termination of the experiment. The UVB-irradiated control group was administered with saline. Irradiated groups received saline, HRCE, or AA. Dorsal skin area of mice was exposed to UVB radiation from LF-215.M lamp (emission peak at $312 \mathrm{~nm}$; Uvitec). Using an electronic controller, UVB dosage at a fixed distance from lamps to the dorsal skin surface of mice was regulated to be $300 \mathrm{~mJ} / \mathrm{cm}^{2}$. The exposure time was 3 min thrice a week for two weeks. At the end of the experiment, the mice were euthanized through cervical dislocation. The dorsal dermis was collected and stored at $-80^{\circ} \mathrm{C}$ for western blotting and fixed in $4 \%$ paraformaldehyde for histological analysis.

Cell viability. Cell viability assay was measured using EZ-Cytox reagent. HaCaT cells $\left(1 \times 10^{5}\right.$ cells $\left./ \mathrm{ml}\right)$ were seeded into 96 -well plates and incubated for $24 \mathrm{~h}$. These cells were then pretreated with $100 \mu \mathrm{g} / \mathrm{ml}$ of HRCE or $50 \mu \mathrm{g} / \mathrm{ml}$ of L-ascorbic acid (AA) for $1 \mathrm{~h}$ and subsequently stimulated with $400 \mu \mathrm{M}$ of tBHP for $16 \mathrm{~h}$. After $16 \mathrm{~h}, 10 \mu \mathrm{l}$ of EZ-Cytox reagent was added to each well. Cells were then incubated for $4 \mathrm{~h}$. The absorbance of each well was then measured at $450 \mathrm{~nm}$ with a microplate reader (Tecan). The concentration of tBHP treatment was determined in previous experiments. $\mathrm{HaCaT}$ cells were treated with various concentrations of tBHP for $16 \mathrm{~h}$, and the survival rate was $\sim 60 \%$ compared to the negative control at $400 \mu \mathrm{M}$ concentration, which was determined to be a suitable concentration for the experiment.

ELISA assay. Culture supernatants of HaCaT cells treated with or without HRCE or AA for $48 \mathrm{~h}$ after UVB radiation were used to measure concentrations of Type I collagen. The protocol used was in accordance with the outlined protocol of the manufacturer of the Kit without modification.

Immunofluorescence staining. In cell culture slide chambers, $\mathrm{HaCaT}$ cells were pretreated with or without HRCE or AA for $24 \mathrm{~h}$ and then stimulated with or without $20 \mathrm{~mJ} / \mathrm{cm}$ of UVB irradiation. These cells were fixed and permeabilized by $100 \%$ ice-cold methanol for $10 \mathrm{~min}$ at $-20^{\circ} \mathrm{C}$. Cells on slides were blocked with $1 \% \mathrm{BSA}$ for $1 \mathrm{~h}$ at room temperature and incubated with collagen antibodies overnight at $4{ }^{\circ} \mathrm{C}$. These cells were then washed with PBS and further incubated with goat anti-mouse IgG, $(\mathrm{H}+\mathrm{L})$ Alexa Fluor ${ }^{\mathrm{TM}}$ plus 488 conjugated secondary antibodies for $1 \mathrm{~h}$. Slides were washed with PBS and mounted with DAP mounting medium. Visualization was under a Zeiss fluorescence Microscope (Zeiss Co.).

Protein extraction. HaCaT cells $\left(2 \times 10^{5}\right.$ cells $\left./ \mathrm{ml}\right)$ were pretreated with HRCE or AA for $1 \mathrm{~h}$ and then treated with UVB irradiation $\left(20 \mathrm{~mJ} / \mathrm{cm}^{2}\right)$. These cells were incubated for $15 \mathrm{~min}$ or $1 \mathrm{~h}$, washed with ice-cold PBS, and centrifuged at $2,000 \mathrm{rpm}$ at $4^{\circ} \mathrm{C}$ for $2 \mathrm{~min}$. The supernatant was discarded and cell pellets were suspended in $0.1 \mathrm{ml}$ of ice-cold RIPA buffer. Tubes were vortexed and incubated on ice for $15 \mathrm{~min}$ with gentle shaking. After incubation, tubes were centrifuged at $12,000 \mathrm{rpm}$ for $15 \mathrm{~min}$ at $4^{\circ} \mathrm{C}$ to pellet cell debris. The 


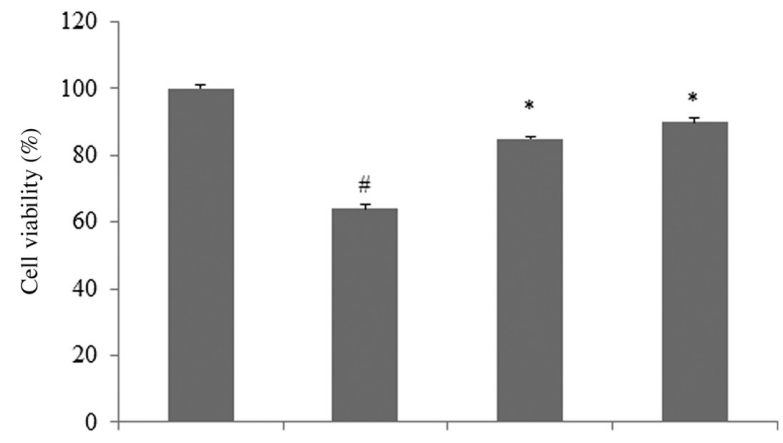

$\operatorname{HRCE}(\mu \mathrm{g} / \mathrm{ml})$

$\mathrm{AA}(\mu \mathrm{g} / \mathrm{ml})$

tBHP $(400 \mu \mathrm{M})$

Figure 1. Effect of HRCE on cell viability in tBHP-stimulated HaCaT cells. HaCaT cells were pretreated with HRCE or L-ascorbic acid (AA) and subsequently stimulated with tBHP. The cells were then incubated with EZ-Cytox reagent, after which cell viability was assessed. Data are presented as the mean $\pm \mathrm{SD} .{ }^{\prime \prime} \mathrm{P}<0.05$ vs. untreated cells; ${ }^{*} \mathrm{P}<0.05$ vs. tBHP treated cells. HRCE, halophyte red ginseng complex extract; tBHP, tert-butyl hydroperoxide; AA, L-ascorbic acid.

supernatant (protein lysates) was transferred into new tubes and stored at $-80^{\circ} \mathrm{C}$ for subsequent use.

For protein extraction from tissue samples, at the end of the UVB irradiation in animal experiment described above, the dorsal dermis was removed and $0.2 \mathrm{~g}$ of the tissue from each mouse was grounded in liquid nitrogen and placed in $0.2 \mathrm{ml}$ of RIPA buffer. Tissues were then incubated on ice for $5 \mathrm{~min}$ before centrifugation at $12,000 \mathrm{rpm}$ for $15 \mathrm{~min}$ at $4^{\circ} \mathrm{C}$. The supernatant was transferred into new tubes and stored at $-80^{\circ} \mathrm{C}$ for subsequent use.

Western blot analysis. Proteins $(45 \mu \mathrm{g})$ were separated on 7.5\% SDS-PAGE gels and transferred onto PVDF membranes. After blocking with 5\% BSA prepared with $1 \%$ Tween-20 in $20 \mathrm{mmol} / \mathrm{l}$ TBS ( $\mathrm{pH} \mathrm{7.4),} \mathrm{membranes} \mathrm{were} \mathrm{then} \mathrm{incu-}$ bated overnight with specific primary antibodies to be assessed. These membranes were washed and incubated with appropriate horseradish peroxidase-conjugated secondary antibody. Protein expression was detected and visualized using a chemiluminescence detection system. The density of each band in an immunoblot was analyzed using ImageJ gel analysis software developed by the National Institutes of Health.

Histopathological examination. Dorsal skin tissues were fixed in $10 \%$ neutral buffered formalin, washed with 1X PBS five times, dehydrated in graduated ethanol, cleared in xylene, embedded in paraffin, and sectioned at $5 \mu \mathrm{m}$ in thickness. Sections were then stained with H\&E for measuring epidermal thickness, trichrome for collagen fiber analysis, and toluidine blue for mast cell quantification. All staining procedures were done using their respective protocols with little or no modifications. Histopathological changes were examined under a light microscope (Leica). Transepidermal water loss (TEWL) was expressed as an average value after five repeated measurements using a gpskin barrier (Amicogen).
Statistical analysis. Data are presented as mean \pm SD. Statistically significant differences among groups were determined by one-way analysis of variance (ANOVA) followed by Tukey's test. Statistically significant difference was considered at $\mathrm{P}<0.05$.

\section{Results and Discussion}

HRCE recovers $t B H P$-induced cell damage. Exposure of UVB can lead to over-production of ROS on the skin, resulting in oxidative stress. Increased intracellular ROS can cause skin diseases, including photoaging, inflammation, and carcinogenesis (17). Therefore, protecting the skin against oxidative stress might be a strategy to prevent UVB-related skin damage. The cytoprotective effect of HRCE in tBHP-stimulated HaCaT cells was investigated. As shown in Fig. 1, stimulated cells without HRCE treatment showed significantly lower survival rates than unstimulated cells. However, the survival rate was significantly higher when cells were treated with $100 \mu \mathrm{g} / \mathrm{ml}$ of HRCE or $50 \mu \mathrm{g} / \mathrm{ml}$ of AA. This implies that HRCE and AA can protect skin against damaging effects of peroxide.

HRCE protects collagen and elastin from cell damage caused by $U V B$. In the skin, collagen and elastin are important for maintaining elasticity, strength, and structure. A decrease in collagen and elastin expression has been observed in photoaged skin $(18,19)$. Therefore, the effect of HRCE on the expression of collagen and elastin in cell damage induced by UVB was investigated. As shown in Fig. 2A, the amount of collagen released into the culture medium of UVB-stimulated cells without HRCE treatment was significantly reduced compared to that in the unstimulated experimental group. Results of immunofluorescence staining (Fig. 2B) also confirmed that collagen density was decreased in cells stimulated by UVB. However, HRCE significantly increased collagen synthesis, which was reduced by UVB. Intracellular collagen and elastin protein expression were examined by western blot analysis (Fig. 2C). Results showed that HRCE recovered UVB-induced collagen and elastin degradation. AA can act as a photoprotective agent. It can stimulate collagen synthesis, protect against damage caused by UVB radiation, and relieve inflammation in the skin (20). In this study, AA also prevented collagen loss. Moreover, HRCE showed similar or slightly less inhibitory effects on collagen and elastin degradation than AA. In general, the reduction of collagen and elastin in the skin is driven by the expression of matrix metalloproteinases (MMP) (21). For this reason, the expression of MMPs was also investigated in this study.

HRCE suppress the expression of MMPs. Exposure to UV can increase the expression of matrix metalloproteinases (MMP) in human skin. MMPs can degrade extracellular matrix (ECM) such as collagen, fibronectin, and elastin and cause photoaging $(21,22)$. The effect of HRCE on protein expression of MMPs called collagenase was investigated. As shown in Fig. 3, HRCE suppressed the expression of MMP-1 and MMP-9 that was increased by UVB. In particular, inhibition of HRCE on MMP-9 expression was superior to that of AA, the reference compound. According 
A

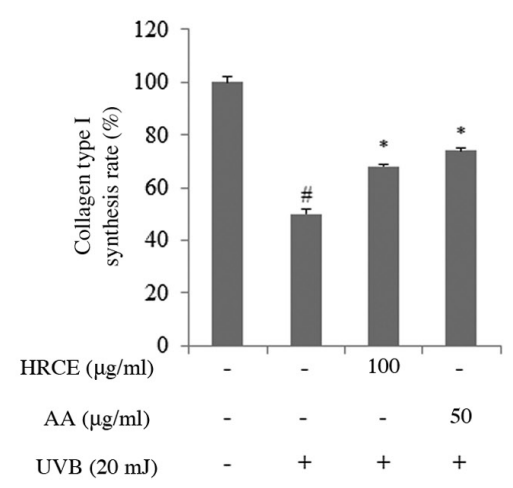

$\mathrm{B} \operatorname{HRCE}(\mu \mathrm{g} / \mathrm{ml}) \quad-\quad-\quad 100$

$\mathrm{AA}(\mu \mathrm{g} / \mathrm{ml}) \quad-\quad-\quad-\quad 50$

UVB $(20 \mathrm{~mJ}) \quad-\quad+\quad+\quad+$
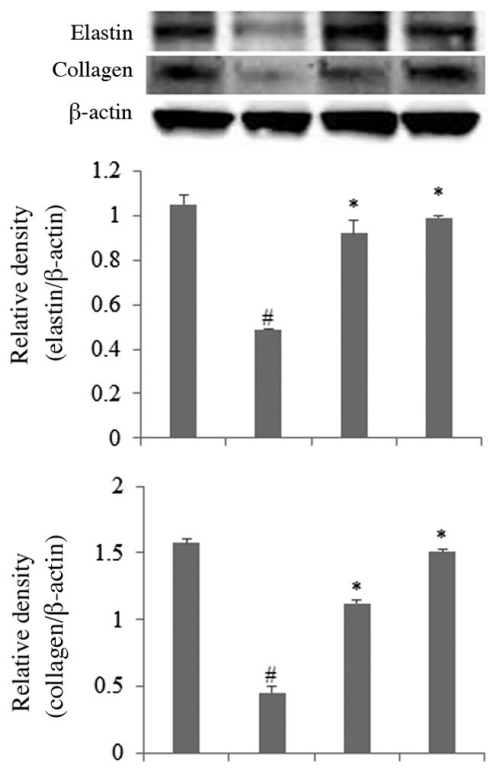

Figure 2. Effects of HRCE on UVB-induced collagen degradation in HaCaT cells. HaCaT cells were pretreated with HRCE or AA and then irradiated with UVB rays. (A) The release of collagen into the culture medium was investigated using an ELISA kit. The expression levels of (B) collagen and elastin were assessed by performing western blotting using total protein extract. Collagen density in the cell structure was examined by $(\mathrm{C})$ immunofluorescence staining. Data are presented as the mean \pm SD. ${ }^{\#} \mathrm{P}<0.05$ vs. untreated cells; ${ }^{*} \mathrm{P}<0.05$ vs. UVB treated cells. HRCE, halophyte red ginseng complex extract; UVB, ultraviolet B; AA, L-ascorbic acid .

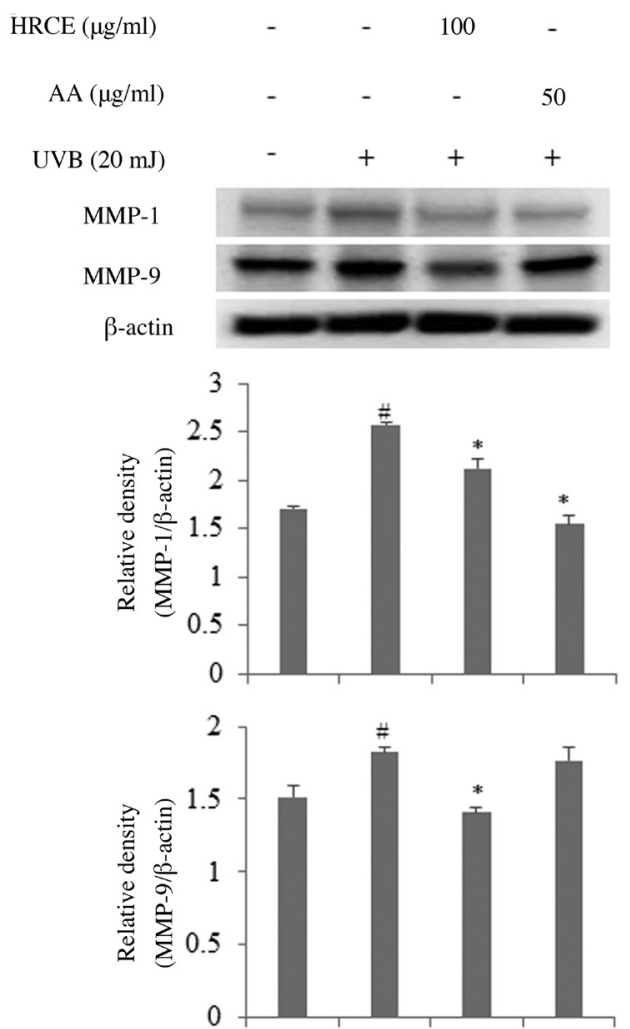

Figure 3. Effects of HRCE on MMP-1 and MMP-9 expression in UVB-irradiated $\mathrm{HaCaT}$ cells. HaCaT cells were pretreated with HRCE or AA and then irradiated by UVB rays. Expression levels of MMP-1 and MMP-9 were investigated via western blot analysis using total protein extract. Data are presented as the mean $\pm \mathrm{SD} .{ }^{*} \mathrm{P}<0.05$ vs. untreated cells; ${ }^{*} \mathrm{P}<0.05$ vs. UVB treated cells. HRCE, halophyte red ginseng complex extract; UVB, ultraviolet $\mathrm{B}$; AA, L-ascorbic acid. to previous studies, MMP-1 degrades Collagen types I and III while MMP-9 degrades Collagen type IV and elastin $(22,23)$. Therefore, HRCE has collagen and elastin protective effect by suppressing the expression of MMP-1 and MMP-9.

HRCE suppresses phosphorylation of Mitogen-activated protein kinase (MAPK) proteins. Next, pathways stimulated by irradiation with UVB were investigated. Fig. 4A shows the degree of phosphorylation of MAPKs in cells exposed to UVB. Results showed that HRCE had no inhibitory effect on phosphorylation of c-Jun N-terminal kinases (JNK) or p38 mitogen-activated protein kinases (p38). However, the phosphorylation inhibitory effect of extracellular signal-regulated kinases (ERK) was significantly evident. As HRCE inhibited the phosphorylation of ERK, the activation of NF- $\mathrm{KB}$ transcription factor by HRCE was then investigated. As a result (Fig. 4B), it was confirmed that the phosphorylation of NF- $\kappa \mathrm{B}$ transcription factor of $\mathrm{HaCaT}$ cells exposed to UVB was significantly inhibited by HRCE. According to previous studies, when the skin is exposed to UV, ROS overproduction occurs, causing MAPK (ERK, JNK, and p38) phosphorylation and NF- $\mathrm{KB}$ activation, which then promotes the expression of MMPs genes and proteins, causing collagen degradation and inflammation $(24,25)$. Thus, the cell protective effect from UVB of HRCE might be due to the inhibition of ERK and NF- $\kappa B$ signaling pathway.

HRCE prevents UVB-induced skin damage and morphological changes. Because HRCE was confirmed to have preventative 

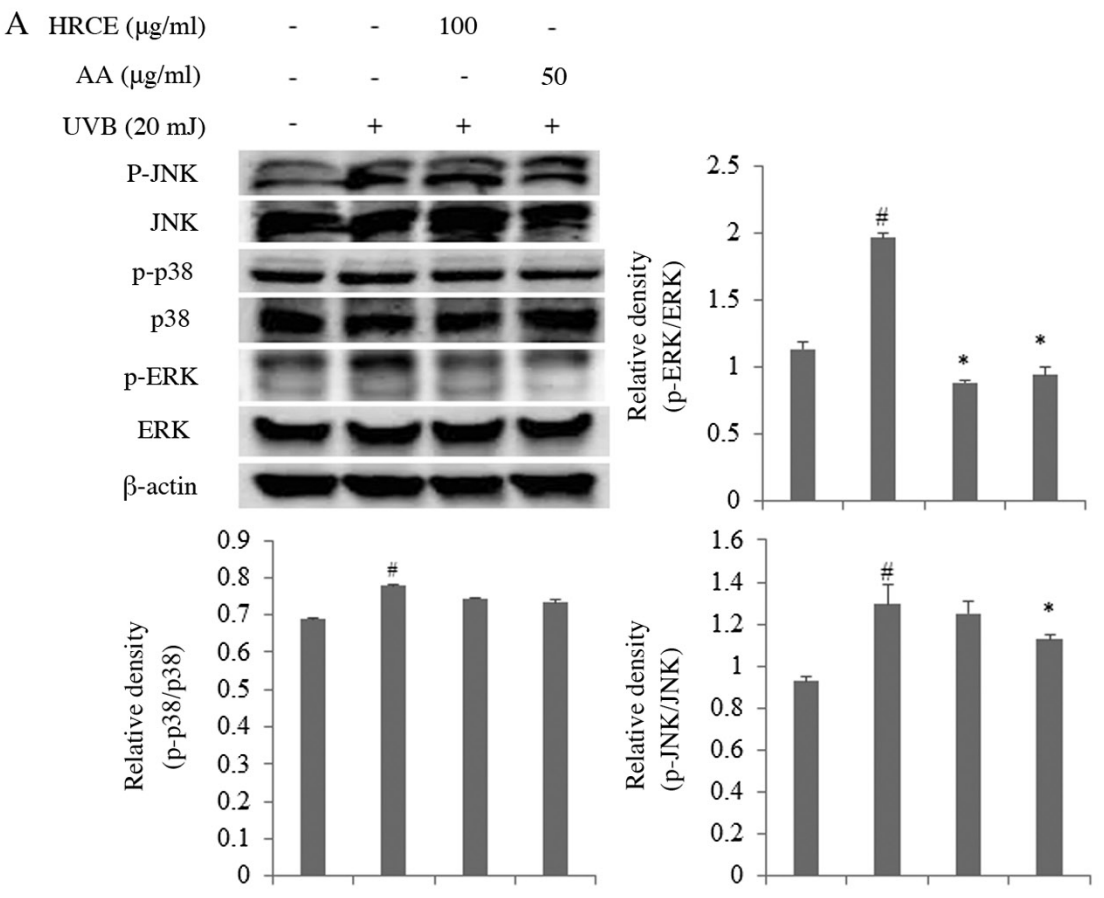

B

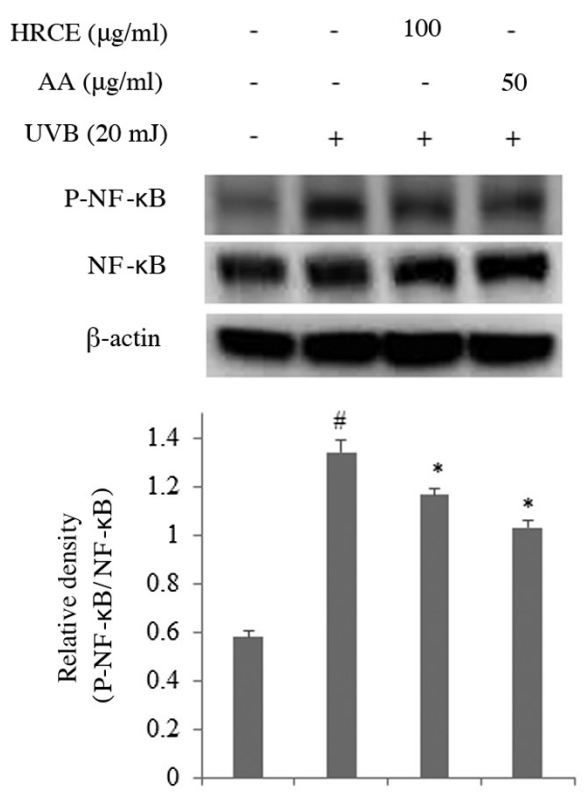

Figure 4. Effects of HRCE on the activation of (A) MAPK and (B) NF-kB. HaCaT cells were pretreated with HRCE or AA and irradiated by UVB rays. Expression levels of MAPK and NF- $\kappa B$ were investigated via western blot analysis using total protein extract. Data are presented as the mean \pm SD. ${ }^{\prime \prime} \mathrm{P}<0.05$ vs. untreated cells; " $\mathrm{P}<0.05$ vs. UVB treated cells. HRCE, halophyte red ginseng complex extract; UVB, ultraviolet B; AA, L-ascorbic acid; p, phosphorylated

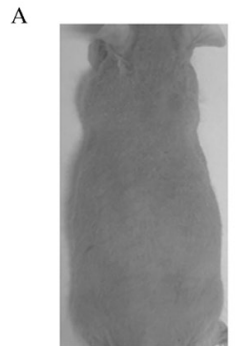

Normal

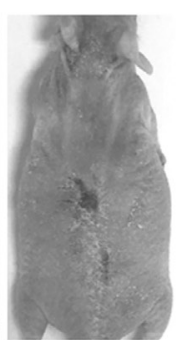

Control

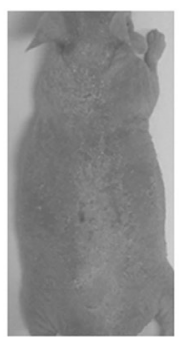

HRCE

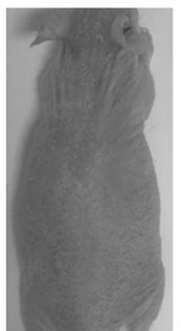

HRCE+AA

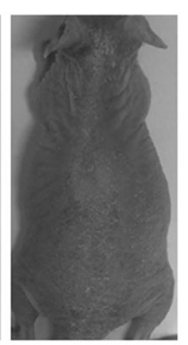

AA

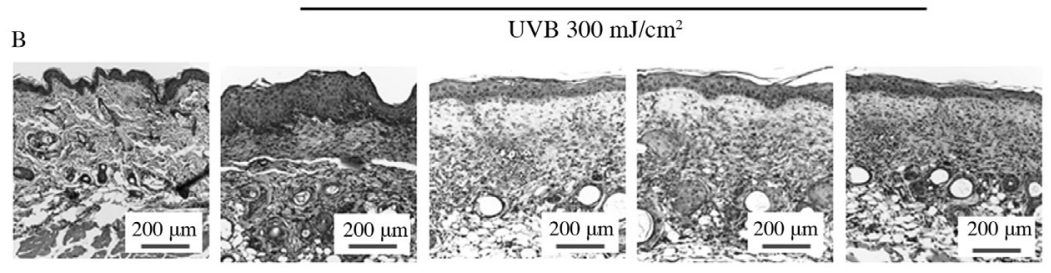

$\mathrm{C}$

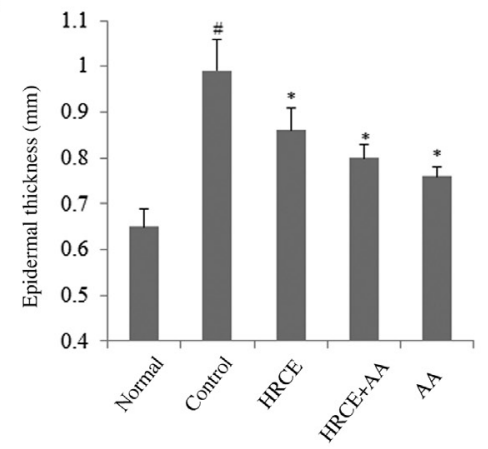

$\mathrm{D}$

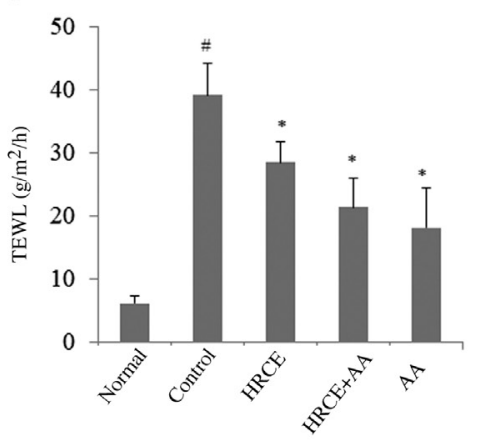

Figure 5. Effects of HRCE on UVB-induced edema and TEWL of mouse skin. Mice were irradiated with UVB three times a week for a total of 2 weeks HRCE and AA were orally administered for 2 weeks, except for the control group. (A) The morphological changes of mice in different groups are presented. (B) Representative hematoxylin \& eosin staining demonstrated epidermal thickness. (C) Epidermal thickness was subsequently measured for each group. (D) TEWL was measured. Data are presented as the mean \pm SD. ${ }^{*} \mathrm{P}<0.05$ vs. normal group; ${ }^{\mathrm{P}}<0.05$ vs. control group. HRCE, halophyte red ginseng complex extract; UVB, ultraviolet B; TEWL, transepidermal water loss; AA, L-ascorbic acid. 

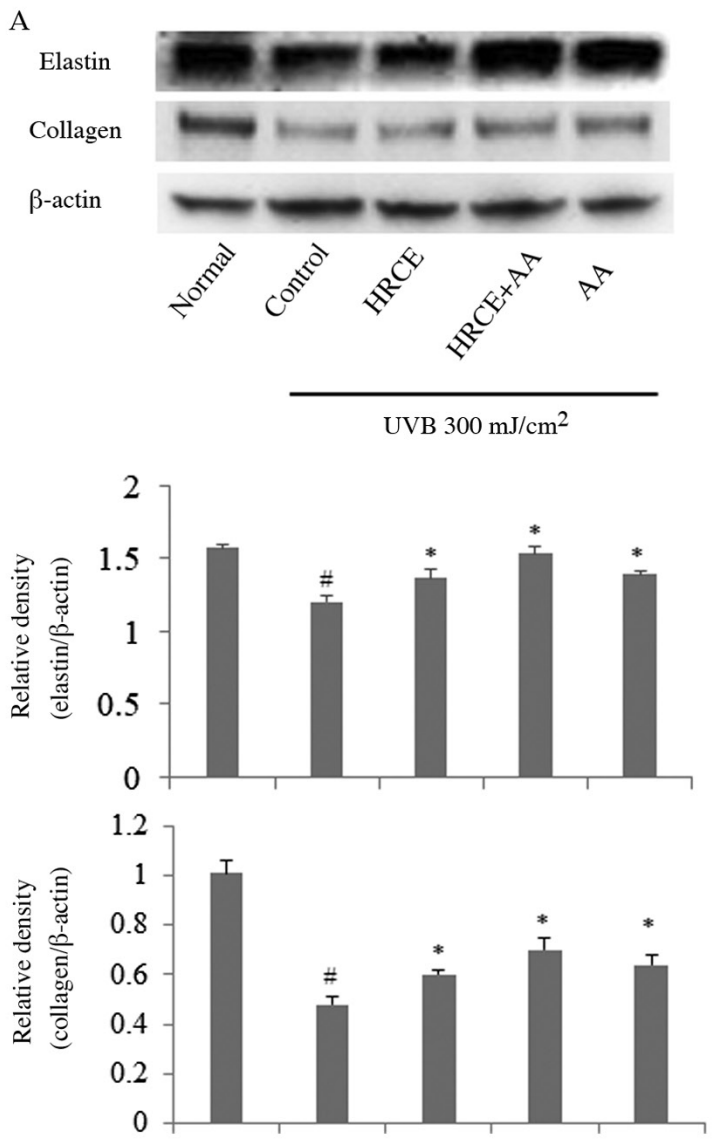

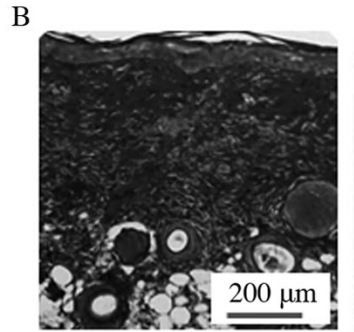

Normal

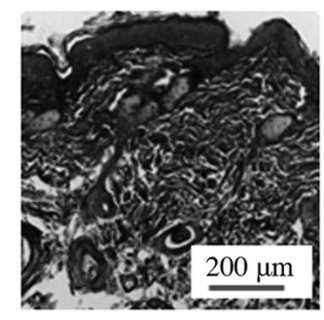

HRCE

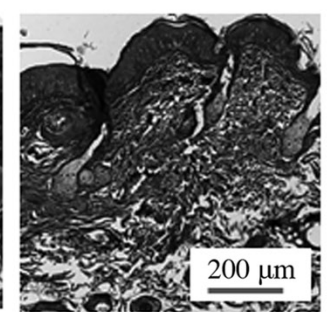

Control

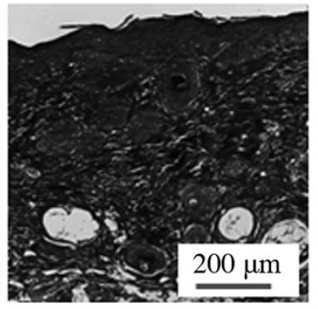

HRCE+AA

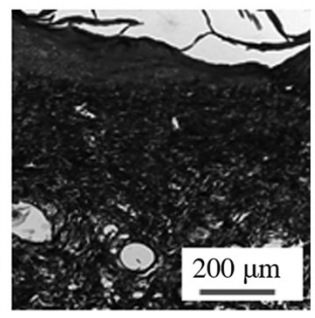

AA

Figure 6. Effects of HRCE on UVB-induced collagen degradation in mouse skin. Mice were irradiated with UVB three times a week for a total of 2 weeks. HRCE and AA were orally administered for 2 weeks, except for the control group. (A) Expression levels of collagen and elastin are investigated by western blot analysis using skin protein extract. (B) Representative trichrome stained tissue of five mice for collagen fiber visualization is presented. Data are presented as the mean $\pm \mathrm{SD}$. ${ }^{\#} \mathrm{P}<0.05$ vs. normal group; ${ }^{*} \mathrm{P}<0.05$ vs. control group. HRCE, halophyte red ginseng complex extract; UVB, ultraviolet B; AA, L-ascorbic acid.

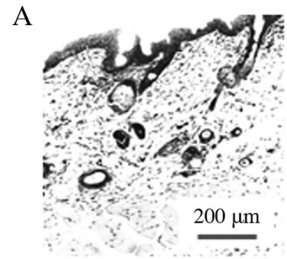

Normal

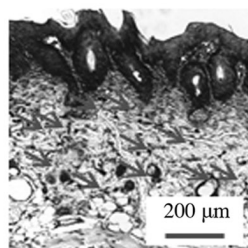

Control

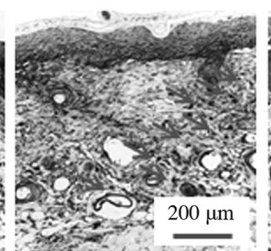

HRCE

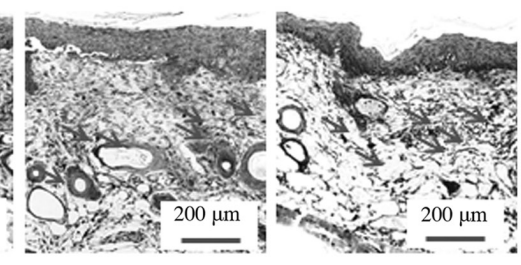

HRCE+AA
AA

$\mathrm{UVB}\left(300 \mathrm{~mJ} / \mathrm{cm}^{2}\right)$

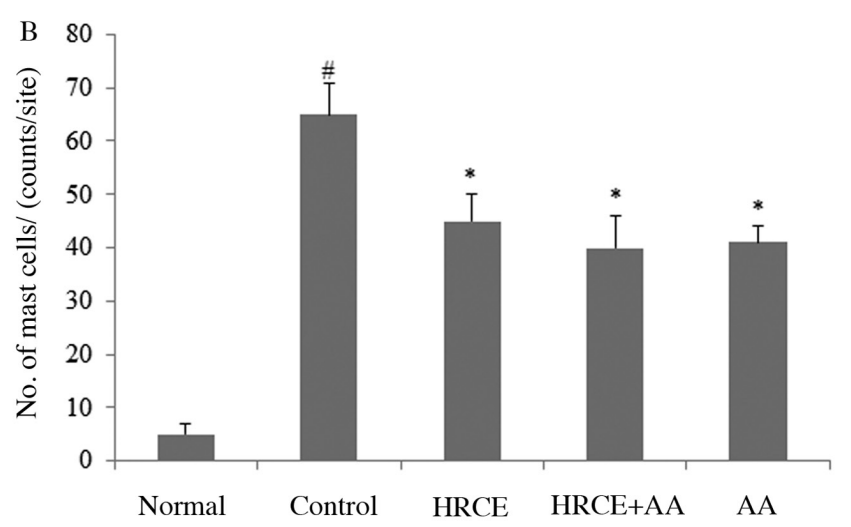

Figure 7. Effects of HRCE on the UVB-induced infiltration of mast cells in mouse skin. Mice were irradiated with UVB. HRCE and AA were orally administered for 2 weeks, except for the control group. (A) Representative images of toluidine blue staining indicating the mast cells from five mice. (B) The number of mast cells from five murine tissue sections was counted under a microscope in a blinded manner. Data are presented as the mean $\pm \mathrm{SD}$. ${ }^{\prime \prime} \mathrm{P}<0.05 \mathrm{vs}$. normal group; "P<0.05 vs. control group. HRCE, halophyte red ginseng complex extract; UVB, ultraviolet B; AA, L-ascorbic acid. 
effect against photoaging and skin damage at the cell level, the efficacy of HRCE was then evaluated in in vivo studies. Improvement of clinical signs and symptoms of UV-induced skin damage by HRCE was evaluated by measuring epidermal thickness and transepidermal water loss (TEWL). Results revealed that repeated irradiation with UVB $\left(300 \mathrm{~mJ} / \mathrm{cm}^{2}\right)$ caused skin edema and dryness (Fig. 5A). As shown in Fig. 5B and C, skin thickness values of UVB irradiated mice were increased. However, when mice were treated with HRCE or AA, skin thickness was reduced. TEWL values of mice in the HRCE group were significantly reduced (Fig. 5D). TEWL is a measure of the function of the stratum corneum. A healthy stratum corneum layer can prevent foreign substances from penetrating the skin. It can also prevent moisture loss (26). The reduction of TEWL with HRCE administration suggests that HRCE can maintain the function of the stratum corneum after UV damage.

HRCE prevents UVB-induced collagen and elastin degradation. Collagen can maintain skin's strength and elasticity along with keratin formation (27). Elastin is a major protein in the extracellular matrix that helps the skin to return to its original shape when the skin is subjected to physical pressure (28). Collagen and elastin are main targets in studies about UV-induced skin damage. Western blot and trichrome staining were performed to investigate the inhibitory effect of HRCE on collagen degradation. According to Fig. 6A, collagen and elastin of mice decomposed by UVB irradiation were recovered by administration of HRCE. Trichrome staining showed that collagen density increased when mice were administered with HRCE (Fig. 6B). Through animal experiments, the improvement effect of HRCE on UV-induced collagen and elastin degradation was consistent with results from cell experiments.

HRCE prevents infiltration of mast cells to the skin. It is known that infiltration of mast cells occurs in skin after UVB exposure (29). Toluidine blue staining showed that mast cells infiltrated the skin after UVB irradiation (Fig. 7A and B). However, the infiltration of mast cells was significantly reduced in skin of mice of the HRCE-administered group and the AA-administered group. Previous studies have reported that mast cells increased by UV in the skin might increase the risk of developing basal cell carcinoma (30). These effects are thought to be due to direct suppression of mast cell invasion or the reduction of oxidative stress by HRCE. These results suggest that HRCE can be used not only to protect collagen and elastin degradation by UVB, but also to prevent skin inflammation and basal cell carcinoma. Therefore, it is considered that there is a need for research on the effects of HRCE on inflammatory cytokines and inflammatory reactions caused by UV rays.

In conclusions, to the best of our knowledge, this is the first study to reveal that HRCE can prevent degradation of collagen and elastin caused by UV exposure using $\mathrm{HaCat}$ cells and hairless mice. It is thought that HRCE can inhibit the expression of MMPs by blocking the activation of MAPK and $\mathrm{NF} \kappa \mathrm{B}$ signaling pathways at the cellular level. In addition, the collagen protective effect of HRCE in cell experiments was consistent with results from animal experiments. Therefore,
HRCE is a potential health functional material that can prevent skin damage caused by UV rays such as skin aging, wrinkles, blemishes, and freckles. It has possible application in the food and cosmetics industry.

\section{Acknowledgements}

Not applicable.

\section{Funding}

This research was supported by a grant from Jeonbuk Research\&Development Program funded by Jeonbuk Province, Republic of Korea (grant no. RA201906-5-C4).

\section{Availability of data and materials}

The datasets used and/or analyzed data during the study are available from the corresponding author on reasonable request.

\section{Authors' contributions}

JYS and SIJ designed the research. JHP, JYS, DNC, HJK and YTL performed the experiments. JYS, BOC and SIJ analyzed the data. SIJ and JYS wrote the manuscript draft. BOC, SIJ and JYS reviewed and edited the final manuscript. SIJ managed the research project. JYS and SIJ confirm the authenticity of all the raw data. All authors read and approved the final manuscript.

\section{Ethics approval and consent to participate}

Mice were handled and experiments were carried out based on Jeonju University Institutional Animal Care and Use Committee guidelines with permission to carry out the experiment obtained from Jeonju University (approval no. JJU-IAC UC-2018-5).

\section{Patient consent for publication}

Not applicable.

\section{Competing interests}

The authors declare that they have no competing interests.

\section{References}

1. Egert M, Simmering R and Riedel CU: The association of the skin microbiota with health, immunity, and disease. Clin Pharmacol Ther 102: 62-69, 2017.

2. Perlish JS, Lemlich G and Fleischmajer R: Identification of collagen fibrils in scleroderma skin. J Invest Dermatol 90: 48-54, 1988.

3. Afaq $\mathrm{F}$ and Mukhtar H: Botanical antioxidants in the prevention of photocarcinogenesis and photoaging. Exp Dermatol 15: 678-684, 2006

4. Rittie L and Fisher GJ: UV-light-induced signal cascades and skin aging. Ageing Res Rev 1: 705-720, 2002.

5. Ho JN, Lee YH, Park JS, Jun WJ, Kim HK, Hong BS, Shin DH and Cho HY: Protective effects of aucubin isolated from Eucommia ulmoides against UVB-induced oxidative stress in human skin fibroblasts. Biol Pharm Bull 28: 1244-1248, 2005. 
6. Wolf ST, Kenney LE and Kenney WL: Ultraviolet radiation exposure, risk, and protection in military and outdoor athletes. Curr Sports Med Rep 19: 137-141, 2020.

7. Lauer-Fields JL, Juska D and Fields GB: Matrix metalloproteinases and collagen catabolism. Biopolymers 66: 19-32, 2002.

8. McCawley LJ and Matrisian LM: Matrix metalloproteinases: They're not just for matrix anymore! Curr Opin Cell Biol 13: 534-540, 2001.

9. Jalmi SK and Sinha AK: ROS mediated MAPK signaling in abiotic and biotic stress-striking similarities and differences Front Plant Sci 6: 769, 2015.

10. Chang L and Karin M: Mammalian MAP kinase signalling cascades. Nature 410: 37-40, 2001.

11. Khan N, Syed DN, Pal HC, Mukhtar H and Afaq F: Pomegranate fruit extract inhibits UVB-induced inflammation and proliferation by modulating NF- $\kappa \mathrm{B}$ and MAPK signaling pathways in mouse skin. Photochem Photobiol 88: 1126-1134, 2012.

12. Yang MH, Kim NH, Heo JD, Sung SH and Jeong EJ: Hepatoprotective effects of Limonium tetragonum, edible medicinal halophyte growing near seashores. Pharmacogn Mag 10 (Suppl 3): S563-S568, 2014.

13. Antioxidant and Anti-inflammatory Activity of Six Halophytes in Korea. Natural Product Sci 24: 40-46, 2018.

14. Wang X, Huang H, Ma X, Wang L, Liu C, Hou B, Yang S, Zhang L and Du G: Anti-inflammatory effects and mechanism of the total flavonoids from Artemisia scoparia Waldst. et kit. In vitro and in vivo. Biomed Pharmacother 104: 390-403, 2018.

15. Sajid M, Khan MR, Shah NA, Ullah S, Younis T, Majid M, Ahmad B and Nigussie D: Proficiencies of Artemisia scoparia against $\mathrm{CCl} 4$ induced DNA damages and renal toxicity in rat. BMC Complement Altern Med 16: 149, 2016.

16. Lee YM, Yoon H, Park HM, Song BC and Yeum KJ: Implications of red Panax ginseng in oxidative stress associated chronic diseases. J Ginseng Res 41: 113-119, 2017.

17. Bickers DR and Athar M: Oxidative stress in the pathogenesis of skin disease. J Invest Dermatol 126: 2565-2575, 2006.

18. Fisher GJ, Datta S, Wang Z, Li XY, Quan T, Chung JH, Kang S and Voorhees JJ: c-Jun-dependent inhibition of cutaneous procollagen transcription following ultraviolet irradiation is reversed by all-trans retinoic acid. J Clin Invest 106: 663-670, 2000.

19. Kwon KR, Alam MB, Park JH, Kim TH and Lee SH: Attenuation of UVB-induced photo-aging by polyphenolic-rich spatholobus suberectus stem extract via modulation of MAPK/AP-1/MMPs signaling in humankeratinocytes. Nutrients 11 $1341,2019$.
20. Petruk G, Del Giudice R, Rigano MM and Monti DM: Antioxidants from plants protect against skin photoaging. Oxid Med Cell Longev 2018: 1454936, 2018.

21. Quan T, Qin Z, Xia W, Shao Y, Voorhees JJ and Fisher GJ: Matrix-degrading metalloproteinases in photoaging. J Investig Dermatol Symp Proc 14: 20-24, 2009.

22. Kim J, Lee CW, Kim EK, Lee SJ, Park NH, Kim HS, Kim HK, Char K, Jang YP and Kim JW: Inhibition effect of Gynura procumbens extract on UV-B-induced matrix-metalloproteinase expression in human dermal fibroblasts. J Ethnopharmacol 137: 427-433, 2011.

23. Pittayapruek P, Meephansan J, Prapapan O, Komine M and Ohtsuki M: Role of matrix metalloproteinases in photoaging and photocarcinogenesis. Int J Mol Sci 17: 868, 2016.

24. Ryu J, Park SJ, Kim IH, Choi YH and Nam TJ: Protective effect of porphyra-334 on UVA-induced photoaging in human skin fibroblasts. Int J Mol Med 34: 796-803, 2014.

25. Tanaka K, Asamitsu K, Uranishi H, Iddamalgoda A, Ito $\mathrm{K}$, Kojima $\mathrm{H}$ and Okamoto $\mathrm{T}$ : Protecting skin photoaging by NF-kappaB inhibitor. Curr Drug Metab 11: 431-435, 2010.

26. Thiele JJ, Dreher F, Maibach HI and Packer L: Impact of ultraviolet radiation and ozone on the transepidermal water loss as a function of skin temperature in hairless mice. Skin Pharmacol Appl Skin Physiol 16: 283-290, 2003.

27. Parvizi J and Kim GK: -Collagen. Chapter 53. In: High Yield Orthopaedics. Parvizi J and Kim GK (eds). WB Saunders, Philadelphia, PA, pp107-109, 2010.

28. Muiznieks LD, Weiss AS and Keeley FW: Structural disorder and dynamics of elastin. Biochem Cell Biol 88: 239-250, 2010.

29. Alard P, Niizeki H, Hanninen L and Streilein JW: Local ultraviolet B irradiation impairs contact hypersensitivity induction by triggering release of tumor necrosis factor-alpha from mast cells. Involvement of mast cells and Langerhans cells in susceptibility to ultraviolet B. J Invest Dermatol 113: 983-990, 1999.

30. Smirnova IO, Kvetnoŭ IM, Anichkov NM, Smirnova ON and Antonova IV: Mast cells in photolesion of the skin and basal cell cancer associated with it. Arkh Patol 67: 26-29, 2005.

This work is licensed under a Creative Commons Attribution-NonCommercial-NoDerivatives 4.0 International (CC BY-NC-ND 4.0) License. 